\title{
Erratum to: Mercury concentrations in tidal marsh sparrows and their use as bioindicators in Delaware Bay, USA
}

\section{Sarah E. Warner • W. Gregory Shriver • Margaret A. Pepper · Robert J. Taylor}

Published online: 26 May 2010

(C) Springer Science+Business Media B.V. 2010

\section{Erratum to: Environ Monit Assess DOI 10.1007/s10661-010-1312-z}

The following sentence should have been included at the end of the "Methods" section:

The online version of the original article can be found at http://dx.doi.org/10.1007/s10661-010-1312-z.

S. E. Warner · W. G. Shriver $(\varangle) \cdot$ M. A. Pepper Department of Entomology and Wildlife Ecology, University of Delaware, Newark, DE 19717, USA e-mail: gshriver@udel.edu

\section{R. J. Taylor}

Trace Element Research Lab, Texas A\&M University, College Station, TX 77843, USA
All $\mathrm{Hg}$ blood levels are expressed in parts per million (ppm) wet weight. 